\title{
Routing Protocols and Movement Models in Opportunistic Networks
}

\author{
Rinky $^{1}$, R.K. Chauhan ${ }^{2}$ \\ 1,2 ( Department of Computer Science \& Applications , Kurukshetra University Kurukshetra, India) \\ Email: bhoriarinky615@gmail.com
}

\begin{abstract}
In recent years during data transmission handling long enduring delay is very difficult task. To handle these delays opportunistic networks are used. In these networks nodes uses store -carry and forward mechanism to forward data messages between intermediate nodes. These intermediate nodes are used to transfer data from source to destination. In opportunistic networks data transmission takes place with the help of standard routing protocols that are already presented in network. In this paper various routing protocols and movement models with their advantages and disadvantages are presented, after that impact of routing protocols and movement models on nodes has been presented means how nodes may behave when routing and movement model is changed.
\end{abstract}

Keywords: Opportunistic networks, routing, movement models, store carry and forward and delays.

\section{INTRODUCTION}

MANET has high mobility due to which there is problem in connectivity. Opportunistic networks are used where there is long period of duration, long delays and lack of connectivity is present during data transmission of nodes. In this environment all existing networks may stop working for this environment opportunistic network is designed. In opportunistic networks there are three nodes used that are source node, intermediate node and destination node, where intermediate node used store and carry forward mechanism . When message comes from source node then intermediate node stores it into its buffer and sends it to the destination nodes when it comes in contact with the destination nodes and message is send to the destination.

A. Technical challenges in Opportunistic networks:

i. Encounter Schedule: In OPPNET messages are transmitted from source to destination only when they encountered with each other or we can say that source can transmit messages through intermediate nodes. Here they only send messages when any encounter has been occurred. So waiting encounter schedule is a challenging task.

ii. Energy: Data transmission between nodes consumes energy and if there is multiple replicated messages a presented in network then energy consumption rate increases hence managing energy in network is a technical challenge.

iii. Storage Capacity: Each node has associated a buffer to store messages during data transmission when two nodes come in range then they try to send all messages that they carried in there buffers to other node. At that time as we know buffers has limited capacity so while receiving messages it may be overflow and drop other receiving messages.

iv. Congestion and Flow Control: To stop congestion during data transmission is also a challenging task.

B. Routing protocols in Opportunistic networks: Data is transmitted in opportunistic networks through various routing schemes like epidemic routing spray and wait routing, direct delivery and first contact routing[[5]6][7].

i. Epidemic routing: Epidemic routings are routing scheme where number of replicas are created at intermediate node and broadcast on network and messages exist on the network even after they delivered to the destination[5].

ii. Spray and wait routing: In spray and wait routing scheme replicas are created and from which node response come it send next data to that node[6]. 
iii. First contact routing: In first contact routing the node that comes first in contact with the intermediate node it forward the data to that node.

iv. Direct delivery routing: In direct delivery routing scheme source node not send data to the intermediate node it contacts direct with the destination node.

C. Movement models in Opportunistic networks: In opportunistic networks several movement models are used that are[7]:

i. Map based movement model: Map based movement model in which a map is created initially to forward the packet to the destination that map defines the path on which packet moves.

ii. Shortest path based movement model: In shortest path based movement model data is moved through the shortest path and for it dijaskra algorithm is used and it is the best movement model in which shortest path is selected and it takes time to choose the shortest path.

iii. Cluster based movement model: In cluster based movement model is same as the map based movement model but in this $\mathrm{x}$-axis and $\mathrm{y}$-axis are also defined.

iv. Random movement model: In random movement model a random path is chosen to forward the data to the destination, this takes less time to forward the packet because there is no algorithm is used to select the shortest path.

\section{RELATED WORK}

Zhu et al.[8] explored the basic relationship between vitality using so as to spare duty cycle operation and system availability in light of the reasonable versatility follow. For straightforwardness, they considered occasional duty cycling of individual hubs, in which every node freely decides the begin time of itself and works for a steady time.

Silva et al.[9]analyzed various routing protocols in perspective of their energy consumption. They used parameter like battery capacity means how much battery is consumed by each node during data transmission.

Alim et al. [10] investigated the auxiliary powerlessness of social-based sending and directing techniques in shrewd systems. Specifically, they presented Community Vulnerability Assessment (CVA), another issue on surveying the execution unwavering quality of crafty directing methodologies in Delay Tolerant Networks (DTN) from a group structure perspective.

Zuo et al. [11], utilizes the benefits such as the facts of the Frame Error Rate (FER) in the physical layer, the most extreme number of retransmissions in the Medium Access Control (MAC) layer and the quantity of transfers in the system layer. Vitality consumption based Target Functions (OF) are conjured for figuring the end-toend vitality utilization of each possibly accessible course for both Traditional Routing (TR) and for our novel Astute Routing (OR), individually.

\section{COMPARATIVE ANALYSIS}

TABLE I MAPPING OF MOVEMENT MODEL WITH CHARACTERISTICS OF NETWORK

\begin{tabular}{|c|l|l|l|l|l|}
\hline & $\begin{array}{l}\text { Node Loss } \\
\text { Ratio }\end{array}$ & $\begin{array}{l}\text { Partitioning } \\
\text { Level }\end{array}$ & $\begin{array}{l}\text { considerable } \\
\text { Delay }\end{array}$ & $\begin{array}{l}\text { Buffer } \\
\text { Constraints }\end{array}$ & $\begin{array}{l}\text { Energy } \\
\text { Constraints }\end{array}$ \\
\hline $\begin{array}{c}\text { MAP based } \\
\text { movement model }\end{array}$ & Low & Low & Low & Low & High \\
\hline $\begin{array}{c}\text { Cluster based } \\
\text { movement model }\end{array}$ & Low & High & Low & High & High \\
\hline $\begin{array}{c}\text { Shortest path } \\
\text { map based } \\
\text { movement model }\end{array}$ & Low & High & High & High & Low \\
\hline $\begin{array}{c}\text { Random way } \\
\text { point movement } \\
\text { model }\end{array}$ & High & High & Low & Low & Low \\
\hline
\end{tabular}


In Table I different movement models are compared with various network characteristics like node loss ratio, partitioning level, buffer constraints and energy constraints etc. As comparative analysis shows that random way point movement model is best model in perspective of energy and buffer constraints as compared to other models.

TABLE II

COMPARISON OF VARIOUS ROUTING WITH PERFORMANCE METRICS

\begin{tabular}{|l|l|l|l|l|l|}
\hline $\begin{array}{l}\text { Routing } \\
\text { Algorithm }\end{array}$ & $\begin{array}{l}\text { Awareness of Routing } \\
\text { Decision }\end{array}$ & $\begin{array}{l}\text { Replication } \\
\text { of messages }\end{array}$ & $\begin{array}{l}\text { Throughp } \\
\text { ut }\end{array}$ & $\begin{array}{l}\text { Message } \\
\text { delay }\end{array}$ & $\begin{array}{l}\text { Delivered } \\
\text { packets }\end{array}$ \\
\hline $\begin{array}{l}\text { Epidemic } \\
\text { routing }\end{array}$ & None & Unlimited & High & Low & Highest \\
\hline $\begin{array}{l}\text { Spray and wait } \\
\text { routing }\end{array}$ & None & Limited & Low & High & Low \\
\hline $\begin{array}{l}\text { First contact } \\
\text { routing }\end{array}$ & - & 1 & Low & high & Low \\
\hline $\begin{array}{l}\text { Direct delivery } \\
\text { routing }\end{array}$ & Direct transmission & 1 & Low & High & Low \\
\hline
\end{tabular}

In Table II comparative analyses of various routing protocols are presented. The analysis has been done on the basis of examination of these routing protocols theoretically. Spray and wait routing is routing in which throughput is high as well as delay is low. Throughput, message delay and delivered packets are network performance metric used for analysis purpose.

\section{PROPOSED WORK}

The proposed work aims is to calculate energy efficiency of each routing schemes and designed an algorithm to calculate energy consumption of each routing schemes. Moreover, it can also be used to design energy aware routing protocols. A node can takes energy in the following phases:

i. Scan phase: In this phase nodes scan their neighbor nodes for transmitting messages to destination. During scanning of nodes consumed energy is known as scan energy.

ii. Sleeping phase: In this phase nodes are inactive means they does not transmit messages. But some energy is still consumed by them.

iii. Transmission phase: Here in this phase energy consumed for transmitting and receiving messages are to be considered.

\section{CONCLUSION}

Opportunistic networks are designed to handle large delay occurred due to partitioning in scenarios. To handle high Energy consummation of each routing in OPPNET is challenging task. In this paper various routing protocols and movement models are discussed with technical challenges while designing OPPNET. After that separate comparative analysis of movement models and routing protocols are presented. Next we present our proposed energy calculation mechanism. In future we try to propose a mechanism by which energy consumption of each routing protocols is calculated and find best routing protocols which computer low energy consumption. 


\section{REFERENCES}

[1] Gao et al., Multidimensional Routing Protocol in Human-Associated Delay-Tolerant Networks, IEEE Transactions On Mobile Computing, Vol. 12 (11), pp. 2132-2144, 2013.

[2] S. Jain, K. Fall and R. Patra., Routing in a Delay Tolerant Network, in Proceedings of ACM SIGCOMM, pp. 145-2008.

[3] Y. Cao et al., Approach-and-Roam (AaR): A Geographic Routing Scheme for Delay/Disruption Tolerant Networks, IEEE Transactions On Vehicular Technology, Vol. 63 (1), pp. 266-281, 2014.

[4] Anders Lindgren, AvriDoria, and OlovSchelen, Probabilistic routing in intermittently connected networks, Proceeding of 1st International Workshop on Service Assurance with Partial and Intermittent Resources , pp. 239-254, 2004.

[5] Anju Rani , Atul Sharma, Dr. Dinesh Singh and Sanjeev Indora, Movement Models based Performance Comparison of Routing Protocols in DTN, in Proceedings of Second International Conference on Emerging Research in Computing, Information, Communication and Applications (ERCICA-14),2014.

[6] Dinesh Singh, SanjeevIndora, Anju Rani and Atul Sharma, Routing Policies \& Strategies in Delay Tolerant Network, International Journal of Engineering Research and Applications (IJERA) ISSN: 2248-9622.

[7] Spyropoulos, T., Psounis, K. \&Raghavendra, C. S., Spray and wait: an efficient routing scheme for intermittently connected mobile networks, in Proceedings of ACM SIGCOMM workshop on Delay-tolerant networking, New York, USA, 2005, pp. 252-259.

[8] Evan P.C. Jones and Paul A.S. Ward, Routing Strategies for Delay Tolerant Networks, University of Waterloo, Ontario, Canada.

[9] Huan Zhou Hongyang Zhao Jiming Chen, Energy Saving and Network Connectivity Tradeoff in Opportunistic Mobile Networks, Globecom 2012 - Ad Hoc and Sensor Networking IEEE Symposium, 978-1-4673-0921-9/12/\$31.00 @2012, pp. 524-529.

[10] Denis Rodrigues-Silva, Antonio Costa and Joaquim Macedo, Energy Impact Analysis on DTN Routing Protocols, ExtremeCom '12, March 10-14, 2012, Zürich, Switzerland. Copyright 2012 ACM 978-1-4503-1264-6/12/03 ...\$10.00. pp 1-6

[11] Md Abdul Alim, Xiang Li, Nam P. Nguyen, My T. Thai, and Abdelsalam Helal, Structural Vulnerability Assessment of Communitybased Routing in Opportunistic Networks, IEEE Transactions on Mobile Computing, DOI 10.1109/TMC.2016.2524571, pp. 1-15.

[12] Jing Zuo, Chen Dong, Hung Viet Nguyen, Soon Xin Ng, Lie-Liang Yang, and Lajos Hanzo, Cross-Layer Aided Energy-Efficient Opportunistic Routing in Ad Hoc Networks, IEEE transactions on communications, vol. 62 (2), Feb. 2014, pp. 522-535. 